\title{
Analysis of the torque converter fluid field
}

\author{
Li Wei \\ School of physics, Baicheng Normal college \\ JiLin Baicheng, China \\ liweiliwei77@163.com
}

Keywords: torque converter; CFD; flow field;Pressure distribution

\begin{abstract}
Advanced hydraulic torque converter is a key component of paper interactive surface technology based on steady-state, the authors established a torque converter flow field calculation model. Using the method of CFD simulated the stator flow field, and the results were validated by experimental data. The flow field characteristic, the velocity and the pressure in the stator were analyzed. The external performance of the torque converter was also calculated.
\end{abstract}

\section{Introduction}

Automotive automatic transmission torque converter is one of the important components, the performance of the vehicle economy and power has a great effect. In order to further improve the performance of the torque converter, it is necessary to torque converter internal flow field in-depth study. By establishing flow model, using steady interactive surface technology, the wheel all the work to link the right torque converter for three-dimensional Flow Field in steady-state analysis, and compared with the experimental results verify the correctness of the analysis results .

2.Flow field calculation model

The torque converter pump wheel, a turbine wheel and the guide component, three impeller inner, outer and leaves a space formed between the impeller plus two non-leaf gate region is formed of the torque converter work flow, model shown in figure 1:

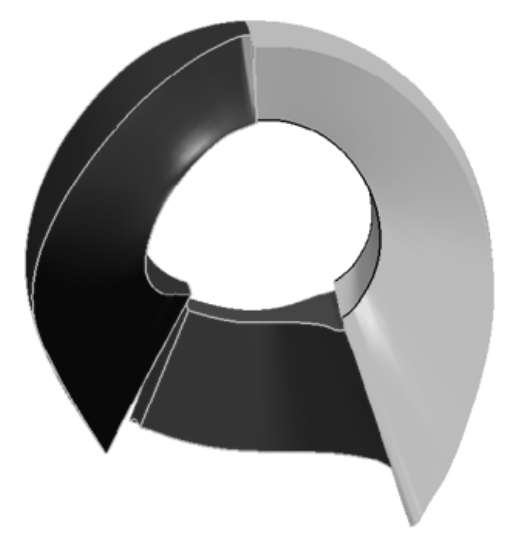

Figure 1. Schematic three-dimensional flow channel

using the coordinate measuring machine torque converter to take each surface point measurements, the establishment of a three-dimensional model of the impeller; extracted from, the three-dimensional model of the impeller flow channel model, taking into account the cyclic symmetry, just take each job rotation a flow channel modeling points; three-dimensional flow model into ICEM software, using the grid generation tool ICEM generated calculation of the flow channel grid model. Figure 2 is a model of the final grid guide wheel. 


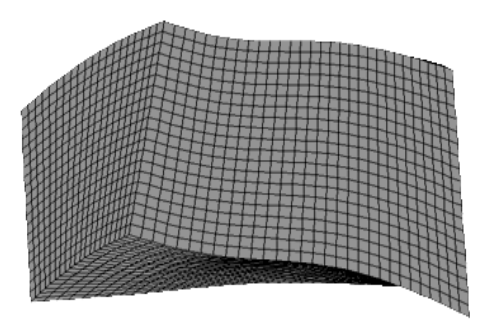

Figure 2. Guide wheel mesh model

Computational analysis of assumptions: rotating reference frame with respect to each, the flow path of the flow field is steady, so the flow field parameters do not change over time; working medium density and viscosity constant; without regard to medium temperature changes; variable All torque converter components are absolutely rigid; addition to the import and export side surface, the working medium can not flow into any other place; upstream impeller working medium flowing into the downstream impeller completely equivalently; in the same conditions, the same each flow impeller flow characteristics in the same channel.

Torque converter for complex flow field turbulent motion, according to the hydrodynamic theory, in order to solve the problem of turbulence, established by the time-averaged N-S equations and k- $\varepsilon$ equations consisting of the control equations:

$$
\begin{aligned}
& \frac{\partial \bar{u}_{1}}{\partial x_{1}}+\frac{\partial \bar{u}_{2}}{\partial x_{2}}+\frac{\partial \bar{u}_{3}}{\partial x_{3}}=0 \\
& \rho \frac{\partial \bar{u}_{i}}{\partial t}+\rho \frac{\partial\left(\bar{u}_{i} \bar{u}_{j}\right)}{\partial x_{j}}=\rho \overline{f_{i}}-\frac{\partial \bar{p}}{\partial x_{i}}+\frac{\partial}{\partial x_{j}}\left(\mu \frac{\partial \bar{u}_{i}}{\partial x_{j}}-\rho \overline{u_{i}^{\prime} u_{j}^{\prime}}\right) \\
& \rho \frac{\partial k}{\partial t}+\rho \overline{u_{j}} \frac{\partial k}{\partial x_{j}}=\frac{\partial}{\partial x_{j}}\left[\left(\mu+\frac{\mu_{t}}{\sigma_{k}}\right) \frac{\partial k}{\partial x_{j}}\right]+\mu_{t} \frac{\partial \overline{u_{i}}}{\partial x_{j}}\left(\frac{\partial \overline{u_{i}}}{\partial x_{j}}+\frac{\partial \overline{u_{j}}}{\partial x_{i}}\right)-\rho \varepsilon \\
& \rho \frac{\partial \varepsilon}{\partial t}+\rho \bar{u}_{i} \frac{\partial \varepsilon}{\partial x_{i}}=\frac{\partial}{\partial x_{i}}\left[\left(\mu+\frac{\mu_{t}}{\sigma_{k}}\right) \frac{\partial k}{\partial x_{j}}\right]+\frac{c_{1} \varepsilon}{k} \mu_{t} \frac{\partial \overline{u_{i}}}{\partial x_{j}}\left(\frac{\partial \overline{u_{i}}}{\partial x_{j}}+\frac{\partial \overline{u_{j}}}{\partial x_{i}}\right)-c_{2} \rho \frac{\varepsilon^{2}}{k}
\end{aligned}
$$

Appearing in the above expression variables:

$x_{i}(i=1,2,3)$ — the three coordinate directions;

$u_{i}(i=1,2,3)$ — - the three components of the velocity vector;

$\left(-\rho \overline{u_{i}^{\prime} u_{j}^{\prime}}\right)$ — the turbulent stress;

$\left(\overline{u_{i}^{\prime} u_{j}^{\prime}}\right)$ — the velocity component of the ripple term;

$k-$ - $a$ unit mass of fluid turbulence kinetic energy;

$\mu_{t}$ —-turbulent viscosity coefficient ;

$\varepsilon$ - - the kinetic energy per unit mass of fluid pulsation dissipation rate;

$c_{2}, c_{3}, \sigma_{k}, \sigma_{\tau}-$ constant.

Calculate the flow channel and outside the ring blade surface boundary conditions for the no-slip wall conditions. Import and export of the working surface road turns steady interactive applications face connection, in Figure 3. V is the velocity, P is pressure, B, T, S, respectively, indicating that the pump wheel, turbine and guide wheel, the subscripts 1 and 2 represent the inlet and outlet. Pump wheel speed $\mathrm{nB}=2000 \mathrm{r} / \mathrm{min}$, in the calculation process pump wheel speed constant turbine speed ratio according to the calculation condition varies. 


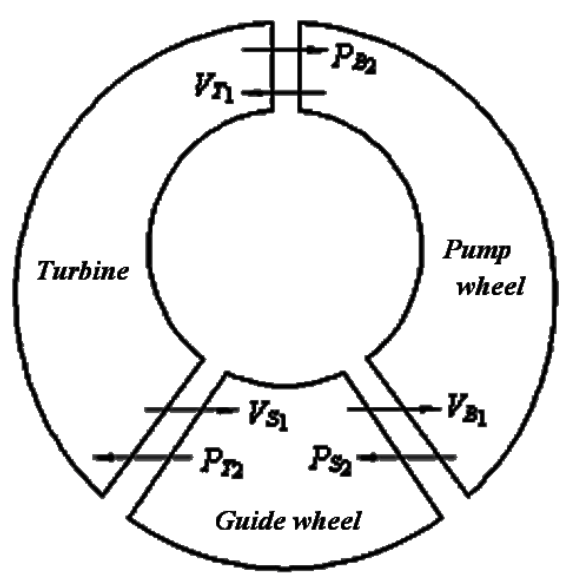

Figure 3. Steady interactive surface

Star-CD CFD software using the flow field numerical calculation, speed-pressure coupling algorithm SIMPLE algorithm, turbulence model using the standard model, using the finite volume method for each unit of velocity and pressure values for solving the entire flow can be obtained field of the velocity and pressure distribution. When the standard calculation of residuals less then 10-3 the calculation process converges.

\section{Flow Field Analysis}

From the start state and highest efficiency performance is good or bad working conditions is to determine the torque converter important factor in performance, through the typical operating conditions of these two guide wheels export plane velocity and pressure distributions were analyzed to obtain information on flow field characteristics. Figure 4 and figure 5 respectively, the calculated field guide rotation velocity and pressure distribution.

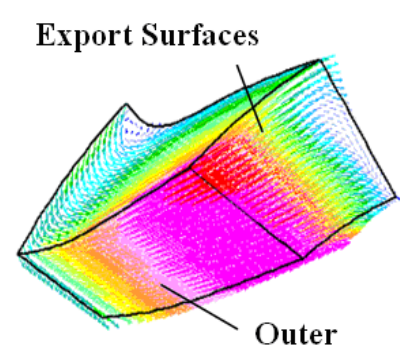

$\mathrm{i}=0$

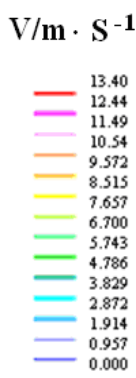

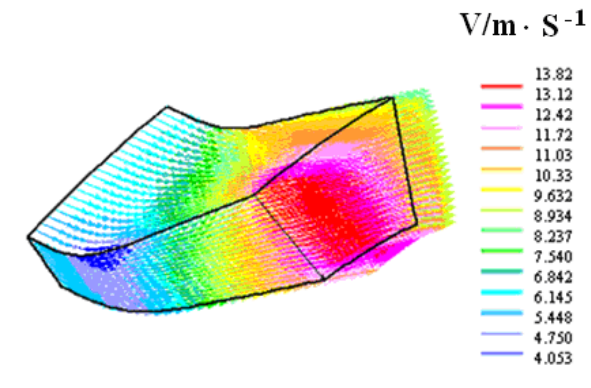

$\mathrm{i}=0.8$

Figure 4. Pump wheel velocity field

The information in figure 4 this conclusion: with the increasing ratio of surface velocity value of imports decreased, imports velocity gradient on the surface did not change significantly, the suction surface at the counter waning. The ratio of the condition $i=0$, countercurrent flow under the impact of the inlet stream flow direction is changed, flow separation occurs on the suction side and the low velocity zone; The ratio of the condition $\mathrm{i}=0.8$, maximum efficiency, has no counter-phenomenon, but the corresponding flow rate of the lower region, near the inner surface of the suction portion of the flow where there is flow in the direction toward the outer ring. $i=0.8$, the pressure on the surface velocity gradient smallest ratio $\mathrm{i}=0$, the pressure on the surface velocity gradient is great condition. The pressure on the surface velocity gradient changes are reflected in the pressure distribution on the surface pressure is the pressure variation in the maximum efficiency point is relatively small. The exit surface has suction reflux occurred; at the highest efficiency point, there is no counter-current, near the outer side of the suction surface have a low flow rate region, the speed of the exit surface of almost the same direction . 


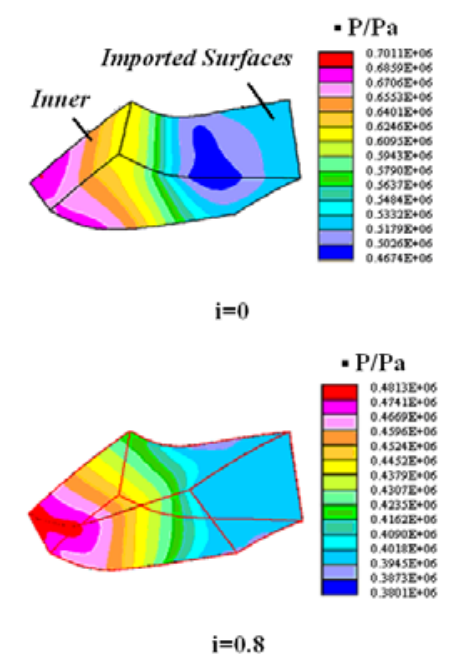

Figure 4. pump wheel pressure field distribution

\section{Summary}

From the start condition, the suction surface in large areas counter, and impact velocity of the oil imported by the change in direction of flow along the outer ring to the exit in

the direction of flow between the two regions of different flow separation occurred many. As the ratio increases, the range is reduced upstream, at maximum efficiency condition disappears when the upstream region, flow separation zone disappears.

(1)Application of non-structural grid and surface technology for interactive three-dimensional steady-state flow field simulation, numerical results with high accuracy, the torque converter can be used for the design and optimization process.

(2)The external characteristics of the calculated results are in good agreement with the experimental results, making the torque converter part of the experiment can be done by software instead of computing, which shorten the development cycle, improve the efficiency of development is of great significance.

(3)Imports surface pressure side to the suction side from the speed increases, the pressure decreases, forming a large velocity gradient and pressure gradients. disappears when the upstream region, flow separation zone disappears.

(4)Imports surface pressure side to the suction side from the speed increases, the pressure decreases, forming a large velocity gradient and pressure gradients.

\section{References}

[1]Lei Yulong, Lin Ge, Tian Hua, Shengpei De Based on the analysis of flow field torque converter retrofit design of Mechanical Engineering .2006,42 (2) :125-128.

[2]JIN-Hyuk Lee, Hoon Lee. Dynamic Simulation of Nonlinear Model-Based Observer for Hydrodynamic Torque Converter System. SAE 2012-01-1228.

[3]Brad Pohl. Transient Torque Converter Performance, Testing, Simulation and Reverse Engineering. SAE 2015-01-0249.

[4]DONG Y, LAKSHMINARAYANA B , MADDOCK D. Steady and unsteady flow field at pump and turbine exits of a torque converter . ASME. 2000, 120: 538 - 548.

[5]SHIN Sehyun, CHANG Hyukjae, ATHAVAL E Mahesh. Numerical investigation of the pump flow in an automotive torque converter .SAE Paper 2015-01-1056. 